\title{
COLORADOSCHOOLOFMINES
}

EARTH•ENERGY•ENVIRONMENT

Division of ECONOMICS AND Business
WORKING PAPER SERIES

\section{U.S. household preferences for climate amenities: Demographic analysis and robustness testing}

Jared C. Carbone

Sul-Ki Lee

Yuzhou Shen

\author{
Working Paper 2019-04 \\ http://econbus-papers . mines.edu/working-papers/wp201904.pdf \\ Colorado School of Mines \\ Division of Economics and Business \\ 1500 Illinois Street \\ Golden, CO 80401
}

October 2019 
Colorado School of Mines

Division of Economics and Business

Working Paper No. 2019-04

October 2019

Title:

U.S. household preferences for climate amenities: Demographic analysis and robustness testing*

Author(s):

Jared C.Carbone

Division of Economics and Business

Colorado School of Mines

Golden, CO 80401

jcarbone@mines.edu

Sul-Ki Lee

Korean Institute for Industrial Economics and Trade

sulkilee@kiet.re.kr

Yuzhou Shen

Division of Economics and Business

Colorado School of Mines

shen@mines.edu

\section{ABSTRACT}

We estimate household demand for climate amenities in the United States with two main objectives in mind: (i) to estimate model parameters with the demographic detail needed to inform climate-induced migration responses in regional population projections for use in climate impact analysis; (ii) to study the robustness of estimates from the existing literature. With respect to the former goal, we find important differences in job-related migration motives by age group and in the overall propensity to migrate among households with children. With respect to the latter aim, our framework shares a common, discrete-choice framework with other, recent attempts to recover climate preferences, allowing us to explore the consequences of a number of key assumptions in a systematic manner. Consistent with the existing literature, we find relatively robust estimates of the impact of the frequency of extreme heat days on household location decisions. The impacts of other, common measures of climate, including the frequency of extreme cold days, average summer and winter temperatures, annual precipitation, humidity and frequency of sunshine, are not identified with precision.

\section{$J E L$ classifications: Q51, Q54, R23.}

Keywords: climate amenities, discrete choice, robustness testing.

${ }^{*}$ We are grateful to David Albouy, Walter Graf, Ryan Kellogg and Hendrik Wolff for supplying us with the dataset used in their study. Thank you to seminar participants at: Arizona State University, Penn State University, Shanghai University, the Front Range Energy Economics Workshop, the Canadian Economics Association Annual Meeting and the Association for Environmental and Resource Economists Summer Conference. We acknowledge support from the Payne Institute for Earth Resources, Colorado School of Mines and the U.S. Department of Energy, Office of Science, as part of research in Multi-Sector Dynamics, Earth and Environmental System Modeling Program. All errors are our own. 


\section{Introduction}

Understanding how a changing climate will affect human well-being is a first-order challenge for climate researchers and policymakers. Among the myriad impacts hypothesized by researchers, perhaps the most direct channel through which society is affected is through the amenities the climate provides in one's local environment. To understand how climate change will impact human well-being, therefore, we need to understand the degree to which the population is exposed to favorable or adverse changes in climate across space.

Moreover, there is a well-documented, long-term pattern of migration from the North to the South and West in the United States. This trend is driven by a combination of job opportunities, affordability and local amenities — climate amenities among them. Thus, understanding the degree to which household may migrate in response to these changes is important as well.

We estimate household demand for climate amenities in the United States. To do so, we employ a discrete-choice model, using household-level observed choices in where to reside within the continental U.S. Combining this information with the historical climate record in these locations allows us to recover estimates of climate preferences after controlling for other factors that are important in driving locational choice, such as job opportunities and cost of living. The model allows us to make predictions regarding the degree to which household may migrate in response to climate change. These predictions may be used as an input to comprehensive assessments of the regional pattern of future populations.

Our analysis is motivated by two main interests. There are a few recent attempts to econometrically estimate the importance of climate amenities to U.S. households (Albouy et al., 2016; Fan et al., 2016; Sinha et al., 2018). ${ }^{1}$ However, none of these studies produces

\footnotetext{
${ }^{1}$ The first study in this field, to our knowledge, is Cragg and Kahn (1997). We focus on comparisons with the three more recent studies here because of commonalities in the research designs and the use of more recent data.
} 
estimates that are differentiated by age at a fine scale. ${ }^{2}$ Our first goal is to produce such estimates as a first step toward generating climate-induced migration flows as an input to detailed, state-level population projections for the U.S. that include the influence of climate change on migration. This is work ongoing.

Understanding the age profile of migrants is important in developing population projections because it determines the fertility and mortality rates of the resulting population. For example, if we find that climate change primarily causes younger families of child-rearing ages to migrate, this will tend to raise the aggregate population growth rate in destination states. A similar and opposite influence would result if primarily older households migrate. Thus, we aim to shed light on whether or not households of different ages exhibit differences in: (i) their overall propensity to migrate; (ii) how they factor job opportunities, cost of living and local amenities (including climate) into the decision to migrate.

Our second motivation is to explore the robustness of the existing literature's findings with respect to a number of key assumptions. Because the research design we employ here shares many common attributes with recent studies, it allows us to explore the consequences of relaxing or changing assumptions in a systematic manner. In particular, all existing studies use different metrics to define climate amenities and the literature provides no guidance as to which (if any) of these metrics should be preferred. We test this assumption. All existings studies also use the same U.S. Census data product (although using different sampling strategies) as the basis for their estimation, the 2000 Decennial Census (5\% sample) IPUMS data. We extend the literature by estimating our models both on the 2000 data and a sample of the American Community Survey (ACS) data from from the period 2006-2010, allowing us to validate the results from the earlier time period and explore the extent to which any important time trends emerge that could impact the use of these estimates in the long-term

\footnotetext{
${ }^{2}$ Both Sinha et al. (2018) and Fan et al. (2016) have strategies for differentiating "young" from "old" households but do not estimate their models for narrow age bins as we do.
} 
studies that are most relevant to climate impact analysis.

As noted, a few recent studies have employed either a hedonic or discrete-choice framework to measure household willingness to pay to avoid climate change in the continental U.S.. These methods use the choice of residential location that households make and prices on local labor and housing markets to infer these values. The studies based on discrete-choice models typically find average damages from an additional day over a high-temperature threshold or an additional degree added to the average summer temperature between $\$ 150-\$ 1,500$ (although the reported measures are not all directly comparable). Albouy et al. (2016), which is based on the hedonic method, finds smaller impacts. ${ }^{3}$

A critical difference between the research designs based on discrete-choice or hedonic methods is the treatment of potential barriers to migration. Sinha et al. (2018) and Fan et al. (2016) follow Bayer et al. (2009), estimating discrete choice models to value climate amenities in the presence of migration frictions. The hedonic approach employed by Albouy et al. (2016) assumes as part of its identification strategy that important frictions do not exist. The consequence is that the importance of climate amenities may be underestimated if migration frictions are indeed important, because migration will not fully arbitrage away differences in standards of living due to differences in climate amenities. The discrete-choice studies in this literature tend to find the migration frictions are empirically significant, a result that would explain the difference in the magnitude of the willingness to pay measures recovered by the two methods.

While past studies have focused on developing measures of the welfare impacts of changes in climate, the issue of migration frictions is critical for predicting migration flows (our primary interest here) as well; if mobility differs by demographic characteristics, this could

\footnotetext{
${ }^{3}$ Studies focusing on countries where impacts on the agricultural sector are expected to be significant also find large impacts (see, for example, Dillon et al. (2011); Mueller et al. (2014)). Finally, there is mixed evidence on international migration induced by climate change, with some finding impacts (Cattaneo and Peri (2015)) and others not (Beine and Parsons (2015)).
} 
be an important influence in shaping the demographics and growth rates of future regional populations.

Our strategy for estimating household preferences with respect to migration frictions and climate amenities builds on all three of these recent studies. Following Bayer et al. (2009), we estimate a discrete choice model using a combination of socio-economic variables from IPUMS (Integrated Public Use Microdata Series) with historical climate data from Schlenker and Roberts (2009) linked at the level of a metropolitan statistical area (MSA) the same dataset employed by Albouy et al. (2016). The discrete choice framework allows us to incorporate migration frictions in recovering household preferences for climate amenities.

Intiutively, we find that job opportunities are an important driver of migration for younger but not older households. Younger households with children are also significantly less willing to migrate overall than other groups. Among the climate measures we consider, only those based on characterizations of extreme heat produce a robust signal in driving household migration decisions. College educated households care more about climate in deciding where to live. There is also significant heterogeneity in climate preferences based on the climate region in which the head of household was born. All of these results add support to the findings of the existing literature.

In our robustness testing, we find that the ACS data from the 2006-2010 time period produces similar results to models based on the 2000 Decennial Census. Specifications of the model which characterize extreme heat using the number of days per year a location exceeds a temperature threshold produce similar, intuitive and statistically-significant results. The impacts of other, common measures of climate including the frequency of extreme cold days, average summer and winter temperatures, annual precipitation, humidity and frequency of sunshine are not identified with precision. Results are also sensitive to the definition of the regional fixed effects used to control for omitted variables in the identification of climate preferences. 


\section{Econometric model of household choice}

We combine household data with historical climate data to estimate demand for climate amenities in a discrete choice framework. In this respect, we build directly upon the work of Albouy et al. (2016), Bayer et al. (2009), Fan et al. (2016) and Sinha et al. (2018). Socieconomic variables are obtained from IPUMS. We use two types of census data - Decennial Census for the year 2000 and American Community Survey (ACS) for the years from 2006 to 2010. Historical climate data are from Albouy et al. (2016) (originating from Schlenker and Roberts, 2009) and linked to the census data sets at the MSA-level.

The econometric strategy (derived largely from Bayer et al. (2009) and Fan et al. (2016)) proceeds in two steps. We first estimate how households respond to wage opportunities and migration costs. We also model heterogeneity in climate preferences at this stage. All location-specific elements of choice are captured as location fixed effects. In the second step, we regress our estimated fixed effects on location characteristics — including climate characteristics.

The indirect utility function is given as

$$
u_{i k}=\ln v_{i k}=\alpha \ln w_{i k}+\delta_{i k}+\theta_{k}+H_{i k}+\epsilon_{i k}
$$

where $v_{i k}$ is indirect utility of household $i$ in MSA $k, w_{i k}$ is the wage that the head of household $i$ would earn in $k, \delta_{i k}$ is the migration friction associated with household $i$ moving to location $k, \theta_{k}$ is the location-specific fixed effect (or mean utility level) asssociated with location $k$ and $\epsilon_{i k}$ is the idiosyncratic individual preference term.

$H_{i k}$ is a preference heterogeneity term which captures the idea that different demographic 
groups may differ in their climate preferences and is defined as

$$
H_{i k}=\sum_{d \in \mathcal{I}_{i}} \sum_{n} \kappa_{d n} c_{n k}
$$

where $d$ indexes the demographic dimensions of heterogeneity, $\mathcal{I}_{i}$ is the set of demographic categories to which household $i$ belongs and $n$ indexes the set of climate amenities, $c_{n k}$. In our base specification, we interact our climate measures of extreme heat days (days with an average temperature over a temperature threshold) and extreme cold days (days below $0^{\circ} \mathrm{C}$ ) with the following demographic categories: climate zone of birth and college education. ${ }^{4}$

We assume that households choose the location that yields the highest utility. If the idiosyncratic error term $\left(\epsilon_{i k}\right)$ takes on a type-I extreme value distribution (Gumbel distribution) gives the probability of household $i$ choosing $k$

$$
\pi_{i k}=\operatorname{Pr}\left(u_{i k} \geq u_{i j}, j \neq k\right)=\frac{\exp \left(u_{i k}\right)}{\sum_{j} \exp \left(u_{i j}\right)}=\frac{\exp \left(\alpha \ln \hat{w}_{i k}+\delta_{i k}+\theta_{k}+H_{i k}\right)}{\sum_{j} \exp \left(\alpha \ln \hat{w}_{i j}+\delta_{i j}+\theta_{j}+H_{i j}\right)}
$$

Equation (2) is a conditional logit model which enables us to recover the parameters of the indirect utility function via maximum likelihood estimation. Estimating Equation (2), however, requires the following two intermediate steps: (i) we observe the wages a household head earned only in their chosen location in the census data, so we must estimate the wages each would have received had they lived elsewhere $\left(\hat{w}_{i k}\right)$; and (ii) migration frictions $\left(\delta_{l k}\right)$ must be modeled.

In the second stage,

$$
\hat{\theta}_{k}=-\beta \ln \hat{p}_{k}+\gamma c_{k}+\eta \ln X_{k}+\xi_{k}
$$

where $\hat{\theta}_{k}$ are the first-stage fixed-effect estimates and the regressors are climate variables

\footnotetext{
${ }^{4}$ Following Fan et al. (2016), we use USDA (U.S. Department of Agriculture) Plant Hardiness Zones for our climate zones.
} 
$\left(c_{k}\right)$, the estimated price of housing services $\left(\ln \hat{p}_{k}\right)$, and other local characteristics $\left(\ln X_{k}\right)$ to estimate $\gamma$ and $\eta$. $\xi_{k}$ is an IID error term.

The price of housing services is estimated from a separate regression where the value of a house or rental payments are regressed on regional fixed effects and other dwelling characteristics. The regional fixed effects represent the degree to which the value of the house for homeowners or rental payments for renters - independent of dwelling characteristics varies over MSAs.

It is possible that an unobserved economic activity in an MSA may affect local housing prices, which may bias the coefficient $\beta$. To address this concern, $\beta \ln \hat{p}_{k}$ term is moved to the left hand side. ${ }^{5}$

$$
\hat{\theta}_{k}+\beta \ln \hat{p}_{k}=\gamma c_{k}+\eta \ln X_{k}+\xi_{k}
$$

\subsection{Wage prediction}

Although we only observe wages in the chosen locations, there are a number of households with similar characteristics in different locations in our data set, which allows us to predict wages in each location. Wages are predicted based on the following model. ${ }^{6}$

$$
\begin{aligned}
\ln w_{i k}=\psi_{0 k} & +\psi_{1 k} W H I T E_{i}+\psi_{2 k} M A L E_{i}+\psi_{3 k} O L D_{i}+\sum_{m=4}^{7} \psi_{m k} E D U_{m i}+\sum_{n=8}^{30} \psi_{n k} O C C_{n i} \\
& +\epsilon_{i k}^{w}+\lambda_{1 k} P\left(R_{B}, R_{D} \mid E D U\right)+\lambda_{2 k} P\left(R_{B}, R_{D} \mid E D U\right)^{2}
\end{aligned}
$$

\footnotetext{
${ }^{5}$ Rather than estimating $\beta$, we directly derive the value of the parameter from the utility function. That is, $\beta=\alpha\left(p_{k} H_{i}^{*} / w_{i k}\right)$ where $H_{i}^{*}$ represents the household's demand function for housing services. We use the median value of $\beta$.

${ }^{6}$ We recognize that an omitted variable bias is likely to exist. For example, motivation might influence educational attainment as well as wage level. This means that $\psi_{m k}$ do not precisely measure the causal effect of education on wages. This does not necessarily bias the wage predictions, however, as long as the bias in $\psi_{m k}$ is consistent across individuals.
} 
where $W H I T E_{i}$ and $M A L E_{i}$ are dummy variables set to be one for white people and male, respectively; $O L D_{i}$ equals 1 if the household head is older than 65 years old and 0 otherwise; $E D U_{m i}$ is educational attainment which is either high school dropout, high school graduate, some college, or college degree; and $O C C_{n i}$ is the type of job occupation. Among the 25 occupations described in the census data (other than "no occupation"), military and extraction are eliminated because people working in those type of jobs are supposed to have restricted mobility. $P\left(R_{B}, R_{D} \mid E D U\right)$ represents the fraction of households born in census region $B\left(R_{B}\right)$ that is currently living in census region $D\left(R_{D}\right)$. This term represents Roy sorting. It captures the notion that some part of the matching between region-specific labor demand and supply is driven by unobservable factors, resulting in bias in $\phi$ terms in Equation (4). We follow Dahl (2002) in correcting for this potential bias. We estimate Equation (4) for each MSA in our sample.

\subsection{Modeling migration frictions}

Following Bayer et al. (2009), we model migration frictions as a function of dummy variables reflecting distance from the place of birth of a household head, with the obvious hypothesis that migration frictions are increasing the further one travels from home.

$$
\delta_{i k}=\mu d_{i k}+\mu^{k i d} d_{i k}^{k i d}
$$

where

$$
d_{i k}=\left\{d_{i k}^{S}, d_{i k}^{R 1}, d_{i k}^{R 2}\right\}, d_{i k}^{k i d}=\left\{d_{i k}^{S, k i d}, d_{i k}^{R 1, k i d}, d_{i k}^{R 2, k i d}\right\}
$$

$d_{i k}^{S}$ equals one if $k$, the location a household head $i$ is found to be residing in, is in his or her birth state. Similarly, $d_{i k}^{R 1}$ and $d_{i k}^{R 2}$ are set to be one if the household head was living in 
the birth census region and macro region, respectively. ${ }^{7}$ The terms labeled "kid" indicate interaction terms that describe the differential cost of migrating for households with children.

It is important to emphasize that our conception of migration frictions is holistic; $\delta_{i k}$ may capture financial outlays associated with moving but it may also capture non-price elements such as the psychic pain a household experiences in moving or cultural differences between origin and destination. Perhaps most importantly, it may capture locational preferences, such as home bias, whereby household tastes are shaped by the characteristics of a location other than those captured by local prices and measurable amenity levels.

This approach to modelling frictions also motivates our choice to differentiate between households with and without children in estimation. A potentially important source of frictions for young families is dependence on family and friends for childcare, a service that would be difficult (or expensive) to reproduce if one moves away. Because an important part of our analysis involves projecting regional populations, we would like to know the fertility profile of migrants. Migrants with children (and young migrants) are most likely to contribute to the regional population of their destination through fertility.

\subsection{Estimating price of housing services}

Housing prices are estimated from the following model.

$$
\ln \rho_{i k}=\ln p_{k}+\lambda_{k} \Lambda_{i}+\boldsymbol{\sigma}_{\boldsymbol{i}}^{\prime} \Phi+\epsilon_{i k}^{p}
$$

where $\rho_{i k}$ is annualized housing prices for home owners and annualized rental payments for renters; $\Lambda_{i}$ is home ownership dummy equals one if the household head owns the house; and

\footnotetext{
${ }^{7}$ Census region and macro region are defined by the U.S. Census Bureau. In the U.S., there are nine census regions (i.e., (1) New England; (2) Mid-Atlantic; (3) East North Central; (4) West North Central; (5) South Atlantic; (6) East South Central; (7) West South Central; (8) Mountain; and (9) Pacific) and four macro regions (i.e., (1) Northwest; (2) Midwest; (3) South; and (4) West).
} 
$\boldsymbol{\sigma}_{\boldsymbol{i}}$ is a vector of dwelling characteristics including number of rooms, number of bedrooms, age of property, and the acreage of property. (The full list of characteristics is displayed in Table 3.) $\ln p_{k}$ is modelled as region fixed effects so that it represents the price of housing services in each region after controlling for home ownership premium and dwelling characteristics.

\section{Data}

Our data for household characteristics originate from the U.S. Decennial Census in 2000 (5\% sample) and the ACS 5-year sample from 2006 to 2010, both available from IPUMS. These data sets provide cross-sectional, individual-level information on demographic and dwelling characteristics, wages and housing prices.

Among the observations in the raw data set, we keep household heads only. Based on this, we assume that household heads are responsible for making residential location decisions. We also restrict our analysis to households who were born and living in the contiguous U.S. in the year of survey. We keep household heads whose MSAs are identified and can be matched with MSA code in the County and City Data Book. Lastly, we select the observations that have income and necessary demographic information such as gender, education and race.

In the wage-prediction regressions, we use the full sample of household heads. Then, we divide the household heads into seven 5-year age bins, ranging from 26 years old to 60 years old. In the first-stage, logit estimation, we limit the sample to a random selection of 80,000 households for each age bin to limit the computational burden of solving the maximum likelihood problem. We do not consider retirees, as we are using wage income as our source of variation for estimating the marginal utility of income.

The main data source for the climate variables is Albouy et al. (2016). Recent historical climate data in Albouy et al. (2016) originate from Schlenker and Roberts (2009). Temperature data is the 1970-1999 average number of days of which daily average temperature 
falls into each temperature bin. There are 222 bins for each $0.9^{\circ} \mathrm{F}$ temperature interval. Other climate variables include annual precipitation, relative humidity and annual days of sunshine.

MSA-level characteristics (e.g., population, per capita income, proportion of white population, per capita crime, etc.) are collected from the 2000 and 2007 County and City Data Book. All county-level data are aggregated to MSA-level, which is the spatial unit of this analysis. An MSA is a geographic area containing more than 50,000 people and a high degree of population density. There are 284 MSAs represented in both of the household data sets. After data cleaning and random sampling of 80,000 households, we are left with 265 MSAs in the census data and $266 \mathrm{MSAs}$ in the ACS data for first-stage, logit regression. In the second stage in which we regress the regional fixed effects on climate variables, the number of MSAs is reduced to 257 due to the missing values of covariates.

Table 1 summarizes the resulting dataset. The top section of the table summarizes the demographic variables. The wage variable represents wage and salary income in dollars. The middle section of the table summarizes the mobility pattern and shows that many household stay close to home - approximately 40 percent of Americans stay in a state where they were born. Climate data in the bottom section of the table are 1970-1999 population-weighted average across MSAs. The last panel summarizes regional characteristics.

\section{Econometric results}

\subsection{Estimating wages and housing services}

Table 2 shows the means (first column) and standard deviations (second column) of the parameters estimated from each MSA-level wage regression in (4). The left-most columns report the results based on the 2000 Decennial U.S. Census dataset. The columns on the 
right report these quantities for the 2006-2010 ACS dataset. Coefficients are consistent with general beliefs - whites earn more than other races, and men earn higher wages than women, for instance. Having a higher educational degree is associated with higher wages. Higherskill occupations earn higher wages. Finally, the results are robust across the different data sets used in our analysis.

Coefficients for the dwelling characteristics in the housing service regressions (equation (6)) are reported in Table 3. Annualized value of a house (or annual rental payments) are increasing to number of rooms, number of bedrooms, and acreage of the property. They are decreasing in age of the structure. The absence of kitchen or plumbing facilities results in lower values/rents of a house. Although we do not report the estimates for the regional fixed effects, the results are intuitive. For example, in the regressions based on the 2000 Decennial Census dataset, the top five cities in terms of estimated price of housing service are San Jose, CA; San Francisco, CA; Santa Cruz, CA; Ventura, CA; New York, NY; and Los Angeles, CA. The cities with lowest price of housing services are Johnstown, PA; Gadsden, AL; Florence, AL; Danville, VA; and Anniston, LA.

\subsection{Recovering the importance of income and migration frictions}

Table 4 describes the results of the conditional logit regressions. It displays the estimation results related to the marginal utility of income ( $\hat{\alpha}$ from equation $(1))$ and the migration friction parameters ( $\hat{\delta}$ from equations $(1)$ and $(5))$. The results reveal that the marginal utility of income is statistically significant for households of all ages, but older households tend to less sensitive to regional differences in wage income. This result is in line with the notion that younger households are more driven by job opportunities in their decision to relocate.

Table 4 reports that migration frictions increase at a decreasing rate as one leaves one's 
birth state, census region and macro region. (Recall that the migration friction parameters - as defined - are cumulative, so that the estimates reported in the table associated with moves out of census region or macro region are incremental.) There are not strong patterns of migration costs by age group with the exception that the presence of children in the household is most relevant to younger households.

The estimates from the two datasets show strong similarities. The estimates marginal utility of income from the more recent, ACS dataset tend to be smaller in magnitude, as pattern that is consistent with labor market evidence that households are migrating with less frequency for job-related reasons (Molloy et al., 2014).

The estimates for the MSA fixed effects (not shown in the table) are intuitive. For example, the city with the highest value of the fixed effects estimate in our analysis (i.e., the most attractive city) is New York, NY, while Jackson, MI is the least attractive.

The preference heterogeneity terms are generally statistically significant and play an important role in recovering the mean estimates of climate preferences in the second-stage regression, and issue which we discuss in greater detail in the following subsection.

\subsection{Recovering the value of climate amenitites}

Table 5 and Figures 1-4 report the results of the second-stage regressions (equation (3) in which we attempt to separately identify the impacts of location-specific amenities. The table reports regressions run by age group for our preferred specification of the model. The figures depict the range of point estimates and statistical significance of the second-stage variables across the constellation of model specifications we have considered. Figure 1 focuses on the "Cold Days" and "Hot Days" temperature variables. Figure 2 focuses on the other

climate-related measures from the second-stage regressions. Figure 3 reports the results of specifications which consider alternative measures of extreme heat. Finally, Figure 4 shows 
the sensitivity of the extreme heat estimates to different specifications of the regional fixed effects used in the second stage to control for omitted variables bias.

Table 5 focuses on the climate-related independent variables in the regression. (The results for the other control variables included in these regressions are reported in the appendix in Tables 7 and 8 for models based on the 2000 Decennial Census and the 2006-2010 ACS respectively.) All climate-related independent variables in the regressions are included in the table with the exception of climate-zone fixed effects. We use USDA plant-hardiness zones to define these fixed effects. Thus our climate-amenity coefficients are identified off of within-zone variation in climate. The "hot days" variable is defined as the number of days per year on which the daily mean temperature exceeds $28^{\circ} \mathrm{C}$. The "cold days" variable is defined as the number of days per year on which the daily mean temperature falls below $0^{\circ} \mathrm{C}$.

We find that the hot days variables are statistically significant across the board and have the expected (negative) sign. We also find some significant results for the cold days variable but only among the regressions based on the ACS dataset. These coefficients have a positive sign. One might have the prior this coefficient would be negative (dislike of cold days). However, it is possible the positive coefficient reflects a preference for climates that have distinct seasons. It is also possible that the $0^{\circ} \mathrm{C}$ threshold is not a sufficiently low temperature to pick up negative impacts. Fan et al. (2016), the most comparable study, find a statistically insignificant and small negative coefficient on this variable. The result is not robust across the datasets we employ however.

While not statistically significant, we also consistently find that households dislike higher relative humidity and prefer higher annual precipitation. All of the results are uniform across the age groups we consider.

Table 6 reports on the climate-heterogeneity terms from the first-stage regressions by age groups and dataset used. We include heterogeneity terms based on the USDA region 
of birth for the head of household as well as for education level. For the regional terms the southeastern U.S. is the omitted category. For education, absence of a college degree is the omitted category. As in Table 5, the cold and hot temperature thresholds are defined as $28^{\circ} \mathrm{C}$ and $0^{\circ} \mathrm{C}$ respectively.

Consistent with the second-stage results, we find that the coefficients related to hot days generally exhibit strong, statistical significance across the board and robustness across the datasets and age groups estimated. Those households originating from California, the Midwest and the West are generally more tolerant of extreme heat than southeasterners. We find that northeasterners are less tolerant of hot days when estimating the model based on the 2000 Decennial Census data but the coefficients become small and positive when we use the ACS data. College-educated households are less tolerant of both extreme heat and cold. The regional results on cold days are statistically significant with less consistency and alternate in sign across the datasets used.

We can use the coefficient estimates on wages and climate heterogeneity from the first stage and the mean, hot-days coefficient from the second stage to calculate the marginal willingness to pay (MWTP) to avoid an additional day above the hot-days threshold. ${ }^{8}$ Households with a head aged 41-45 have an nationwide average willingness to pay to avoid an additional hot day annually of $\$ 557$ or $\$ 755$ depending whether the 2000 Decennial Census or ACS estimates are used. These values are somewhat larger than those reported by Fan et al. (2016) or Albouy et al. (2016) but of the same order of magnitude. Of the two studies, the Fan et al. (2016) research design is most comparable. A difference (which we explore further in the following section) is that they use a temperature threshold of days where the daily high temperature exceeds $90^{\circ} \mathrm{F}$, a significantly lower bar than a threshold based on the daily average temperature over $28^{\circ} \mathrm{C}\left(82^{\circ} \mathrm{F}\right)$ as we use here. Thus, larger estimates are

\footnotetext{
${ }^{8}$ We can calculate the MWTP for amenity $n$ as $M W T P_{n}=\frac{\partial u_{i k}}{\partial c_{n k}} \frac{\partial \hat{w}_{i k}}{\partial u_{i k}} \bar{w}$, where $\bar{w}$ is the mean wage level from the 2000 Decennial Census reported in Table 1.
} 
plausible because we are studying more extreme climate events.

\subsubsection{Robustness testing}

We know turn to Figures 1-4 to explore the results of additional robustness tests conducted with the second-stage model. The figures are box plots with the individual point estimates derived from the different specifications of the model overlaid. The horizontal black line indicates the mean value of the estimates. The vertical extent of the box indicates the range of estimates that lie between the 25th and 75th percentiles. Black points indicate point estimates that are statistically significant at the $95 \%$ level.

Figures 1 shows estimates of the hot and cold days variables. Figure 2 shows estimates of the other climate variables (humidity, precipitation and sunshine). All regression models use the $28^{\circ} \mathrm{C}$ definition of hot days. We vary the regressions to produce the different point estimates along a few dimensions. First, we include regressions for the different age groups and datasets described in Table 5. In addition, we also report on models that pool all the age groups. Because the different temperature measures (hot days, cold days, average annual temperature) are highly correlated in many climates, we also include versions of the model in which the average annual temperature variable is omitted.

Figures 1 shows that the hot-days estimates are tightly clustered around a mean value of approximately -0.01 and statistically significant (with one exception.) In contrast, the colddays variable shows less robustness in terms of both statistical siginficance and values of the point estimates. With respect to the other climate measures included in the second-stage regressions, Figure 2 shows that - while all three variables show consistent and intuitive patterns in the signs of the point estimates - they are imprecisely estimated.

Figure 3 explores specifications of the second-stage model based on alternative measures of extreme heat. We have chosen our candidate measures to match those used in other, recent studies of the value of the climate amenities that employ similar, discrete choice 
frameworks. As noted, Fan et al. (2016) uses a measure similar to the one used in our central specifications with the difference that it is based on a daily maximum temperature of $90^{\circ} \mathrm{F}$ instead of a daily average temperature of $28^{\circ} \mathrm{C}\left(82^{\circ} \mathrm{F}\right)$. Sinha et al. (2018) instead use the average summer temperature as their measure of extreme heat. Because this measure is so collinear with average annual temperature, they do not include this latter variable in their second-stage regressions. Our central specification and the model used by Fan et al. (2016) include this variable.

The figure compares second-stage estimates based on these temperature measures as well as ones based on specifications in which our threshold temperature is lowered $\left(26^{\circ} \mathrm{C}, 79^{\circ} \mathrm{F}\right)$ or raised $\left(30^{\circ} \mathrm{C}, 86^{\circ} \mathrm{F}\right)$ from our central case. Here we have omitted the average annual temperature variable from all specifications in order to increase the degree of comparability between the the Sinha-et-al-inspired measure and the others.

The three specifications based on average daily temperature with increasingly high thresholds follow an intuitive pattern; lower thresholds result in smaller household impacts. The thresholds at $26^{\circ} \mathrm{C}$ and $28^{\circ} \mathrm{C}$ appear to be robustly estimated, although the lower threshold produces some insignificant results due to the fact that the mean point estimate is relatively close to zero. The $30^{\circ} \mathrm{C}$ threshold shows a wider spread of values as well as some insignificant results. This is likely due to lack of variation in the historical climate data; there are relatively few parts of the country that have a significant number of days per year that exceed this threshold, and many fall within in the desert southwest.

Similarly, the estimates produced by Fan-et-al-inspired measure seem in line with the other temperature-threshold measures; it is precisely estimated and of a magnitude that is intuitive compared to the other measures and similar to the point estimates produced by the original Fan et al. (2016) study. We find a willingness to pay from our Fan-et-al-inspired specification of approximately $\$ 500$ for households aged $41-45$, whereas the original Fan et al. (2016) study reports $\$ 144$ to $\$ 300$ across all ages groups. 
The Sinha-et-al-inspired measure is not directly comparable to the others in the sense that there is not a simple relationship between the climate impact of a degree increase in the average summer temperature and an additional day above a temperature threshold. In general, however, a degree increase in summer temperature should be larger than the effect of an additional day above any of the other measures described here on the average summer temperature. ${ }^{9}$ We also find that the central tendency of the estimates produce by it are negative in sign and estimated with less precision than the other measures; the spread in the estimates around the mean is considerably larger and only one of the estimates is statistically significant at the $95 \%$ confidence level. ${ }^{10}$ We find an average willingness to pay to avoid a $1^{\circ} \mathrm{F}$ increase in summer temperature for households 41-45 using our Sinha-et-alinspired specification of $\$ 2218$. In contrast, Sinha et al. (2018) report an average of $\$ 627$ for prime-aged households or $\$ 1424$ for older households.

Finally, we examine the consequences of a change the definition of the regional fixed effects used to control for omitted variable bias in the second-stage regressions. Our central specification included fixed effects based on five USDA plant hardiness zones. Alternatively, we have produced a set of estimates using a definition based on the same nine census regions that define our migration friction parameters. ${ }^{11}$ Finally, we omit the fixed effects entirely from the second stage.

\footnotetext{
${ }^{9}$ For example, suppose the average summer (June through August) temperature is $73^{\circ} \mathrm{F}$ (the mean reported by Sinha et al. (2018)). Because of this, we would expect the "Summer" point estimates to be larger in magnitude, and they are as judged by the mean values. Adding an additional day at $83^{\circ} \mathrm{F}\left(28^{\circ} \mathrm{C}\right)$ would affect the average in the following way: $(73 * 91+83) / 92=73.1$. That is, it would increase the mean by a tenth of a degree.

${ }^{10} \mathrm{It}$ is worth noting a few differences between the Sinha-et-al-inspired results presented here and the original research design described by Sinha et al. (2018). First, those authors use a different set of control variables in their second-stage regressions, although there is significant overlap in the types of variables included. A priori, neither list seems obviously preferred. Second, Sinha et al. (2018) take a different approach to capturing climate-preference heterogeneity, employing a random-effects model. Here we use a fixed-effects approach defined over region of birth and education level. Finally, we follow Fan et al. (2016) by including second-stage region fixed effect to help soak up omitted variables while Sinha et al. (2018) do not.

${ }^{11}$ Nine US Census regions: New England, Mid-Atlantic, East North Central, West North Central, South Atlantic, East South Central, West South Central, Mountain, Pacific. Five USDA hardiness zones: California, West, Midwest, Northeast, Southeast.
} 
Figure 4 depicts box plots in same format as the previous figures with the different fixed effects definitions on the x-axis and the values of the hot-days point estimates on the y-axis. Again, we restrict the sample of models to those based on the $28^{\circ} \mathrm{C}$ definition of hot days. The results based on the specifications with no fixed effects and those based on the USDA zones produce estimates of similar sign, magnitude and statistical significance. In contrast, when the finer-spatial-scale census regions are used, the point estimates are smaller in magnitude and — as a result — less likely to be statistically different from zero. We would expect the fixed effects to be more effective in purging the model of omitted variable bias when defined over finer spatial scales because because there are less likely to be regional differences within each region that are corrolated with variation in climate. This would suggest that estimates based on the census regions should be preferred. On the other hand, there is also less climate variation at these smaller scales, which makes it more difficult to precisely estimate the coefficients of interest.

\section{Concluding remarks}

Here we have used a model of how households choose where to live to reveal the importance of climate in shaping this decision. The discrete-choice framework we employ also allows us to measure the psychological cost of moving from one's place of birth. We have done so as a first step toward developing projections of migration flows across the continental U.S. in response to climate change. These migration flows will inform comprehensive projections of regional population in ongoing research. We have also extended the economic literature on household valuation of climate amenities. We have done so by estimating the model in greater demographic detail than previously had be done. And by using a research design that shares many common attributes with recent studies, we have explored how changing key assumptions impacts the results. 
We find important differences in the motives for migration across household ages, although value of climate amenities themselves appear to be relatively uniform in this dimension. We confirm the main finding of the past literature - that measures of extreme heat produce the most robust signal in the data. We find less support for the conclusion that extreme cold or other measures of climate can be measured with precision. We also find evidence of sensitivity to the definition of the regional fixed effects used to combat omitted variables bias. Thus, there is a tension between employing finer-scale controls and having sufficient climate variation in the data to recover estimates of its impacts on household choices.

There are a number of directions future research could profitably pursue. First, there are long-term trends in migration and labor markets that have resulted in household relocating for job opportunities with less frequency (Molloy et al., 2014), and that local amenities (including climate) have taken on greater importance in making location decisions — particularly among high-skill workers (Diamond, 2016). Efforts to include these trends and how they interact with local labor and housing markets in a richer way would be useful in the pursuit of using estimates of sorting models to inform migration projections.

The structural approach to modeling household choice described here is likely to be an important maintained set of assumptions if the ultimate aim of the analysis is to conduct welfare analysis of climate impacts. However, if one only wishes to prediction aggregate migration flows, it seems likely that a simpler, reduced-form approach could be taken. For example, the ICLUS model developed by the U.S. Environmental Protection Agency takes a gravity approach to modeling the influence of climate on migration (EPA., 2010). It is unclear, however, if the reduced-form described in the model is consistent with the underlying economic theory that drives the structural approaches discussed here. Work to bridge this gap and provide "micro-foundations" for gravity-based migration models may suggest different estimation strategies or be able to make use of different sources of data. 
Finally, while the direct experience of climate through the measures described in the existing literature seems like a natural starting point, there are other channels through which climate could affect household locational choice. Regional water scarcity, sea-level rise and extreme weather events (such as hurricanes, tornados and extreme precipitation events) as well as the indirect effects of climate on regional industries could all factor importantly into these decisions. Future work should aim to incorporate these considerations as well. 


\section{References}

Albouy, David, Walter Graf, Ryan Kellogg, and Hendrik Wolff, "Climate amenities, climate change, and American quality of life," Journal of the Association of Environmental and Resource Economics, 2016, 3 (1), 205-246.

Bayer, Patrick, Nathaniel Keohane, and Christopher Timmins, "Migration and hedonic valuation: The case of air quality," Journal of Environmental Economics and Management, 2009, 58 (1), 1-14.

Beine, Michel and Christopher Parsons, "Climatic factors as determinants of International Migration," The Scandinavian Journal of Economics, 2015, 117 (2), 723-767.

Cattaneo, Cristina and Giovanni Peri, "The Migration Response to Increasing Temperatures," NBER Working Paper 216222015.

Cragg, Michael and Matthew Kahn, "New Estimates of Climate Demand: Evidence from Location Choice," Journal of Urban Economics, 1997, 42 (2), 261 - 284.

Dahl, Gordon B., "Mobility and the Return to Education: Testing a Roy Model with Multiple Markets," Econometrica, 2002, 70 (6), 2367-2420.

Diamond, Rebecca, "The Determinants and Welfare Implications of US Workers' Diverging Location Choices by Skill: 1980-2000," American Economic Review, March 2016, 106 (3), 479-524.

Dillon, Andrew, Valerie Mueller, and Sheu Salau, "Migratory responses to agricultural risk in northern Nigeria," American Journal of Agricultural Economics, 2011, 93 (4), 1048-1061. 
EPA., U.S., "ICLUS Tools and Datasets (Version 1.3.2)," Technical Report EPA/600/R09/143F, U.S. Environmental Protection Agency 2010.

Fan, Qin, H. Allen Klaiber, and Karen Fisher-Vanden, "Does Extreme Weather Drive Interregional Brain Drain in the U.S.? Evidence from a Sorting Model," Land Economics, 2016, 92 (2), 363-388.

Molloy, Raven, Christopher L Smith, and Abigail K Wozniak, "Declining migration within the US: the role of the labor market," Technical Report, National Bureau of Economic Research 2014.

Mueller, Valerie, Clark Gray, and Katrina Kosec, "Heat stress increases long-term human migration in rural Pakistan," Nature climate change, 2014, 4 (3), 182-185.

Schlenker, Wolfram and Michael J Roberts, "Nonlinear temperature effects indicate severe damages to US crop yields under climate change," Proceedings of the National Academy of sciences, 2009, 106 (37), 15594-15598.

Sinha, Paramita, Martha L. Caulkins, and Maureen L. Cropper, "Household Location Decisions and the Value of Climate Amenities," Journal of Environmental Economics and Management, 2018, 92, 608-637. 


\section{Tables}

Table 1: Descriptive Statistics

\begin{tabular}{|c|c|c|c|c|}
\hline & Mean & Std. Dev. & Mean & Std. Dev. \\
\hline Demographic characteristics & \multicolumn{2}{|c|}{ US Census 2000} & \multicolumn{2}{|c|}{ US ACS 2006-2010 } \\
\hline Age (years) & 40.617 & 10.368 & 42.378 & 10.885 \\
\hline Wage (USD) & 43482.230 & 42697.430 & 57814.110 & 59971.110 \\
\hline White $(\%)$ & 0.816 & - & 0.829 & - \\
\hline Male $(\%)$ & 0.662 & - & 0.555 & - \\
\hline \multicolumn{5}{|l|}{ Education } \\
\hline High School Dropout (\%) & 0.080 & - & 0.044 & - \\
\hline High School Graduate (\%) & 0.240 & - & 0.211 & - \\
\hline Some College (\%) & 0.339 & - & 0.339 & - \\
\hline College Graduate (\%) & 0.342 & - & 0.406 & - \\
\hline \multicolumn{5}{|l|}{ Mobility pattern } \\
\hline \multicolumn{5}{|l|}{ People who have moved to outside of their: } \\
\hline birth state & 0.415 & - & 0.420 & - \\
\hline birth census region & 0.318 & - & 0.322 & - \\
\hline birth macro region & 0.255 & - & 0.255 & - \\
\hline the & \multicolumn{2}{|c|}{$1,397,050$} & \multicolumn{2}{|c|}{$1,862,054$} \\
\hline Climate and geographic data & \multicolumn{4}{|c|}{ Albouy et al (2016) } \\
\hline \multicolumn{5}{|l|}{ Days per year with average temperature: } \\
\hline$>28^{\circ} \mathrm{C}$ & 14.951 & 22.131 & 14.717 & 21.400 \\
\hline$<0^{\circ} \mathrm{C}$ & 38.124 & 36.103 & 38.124 & 36.103 \\
\hline Average annual precipitation (inches) & 39.970 & 13.997 & 40.177 & 13.868 \\
\hline Average annual relative humidity (\%) & 64.229 & 8.006 & 64.382 & 7.774 \\
\hline Average annual sunshine ( $\%$ of available daylight) & 60.203 & 7.652 & 60.145 & 7.519 \\
\hline Average distance to sea (miles) & 275.844 & 274.464 & 275.554 & 274.713 \\
\hline Average distance to Great Lake (miles) & 754.631 & 683.857 & 751.652 & 680.551 \\
\hline Average land slope (degrees) & 1.647 & 1.931 & 1.639 & 1.933 \\
\hline$N$ & \multicolumn{2}{|c|}{257} & \multicolumn{2}{|c|}{257} \\
\hline Regional characteristics & \multicolumn{2}{|c|}{$C C D B 2000$} & \multicolumn{2}{|c|}{$C C D B 2007$} \\
\hline Population (million) & 0.755 & 1.194 & 0.823 & 1.280 \\
\hline Number of manufacturing establishments & 963.377 & 1783.471 & 937.202 & 1657.101 \\
\hline Government expenditure per capita ( 1,000 USD) & 5.272 & 2.068 & 6.811 & 2.667 \\
\hline Property taxes to total taxes & 0.738 & 0.160 & 0.733 & 0.158 \\
\hline Income per capita (1,000 USD) & 25.262 & 4.785 & 31.901 & 6.059 \\
\hline Proportion of White & 0.790 & 0.116 & 0.830 & 0.108 \\
\hline Number of crime per capita & 0.043 & 0.014 & 0.042 & 0.013 \\
\hline$N$ & \multicolumn{2}{|c|}{257} & \multicolumn{2}{|c|}{257} \\
\hline
\end{tabular}


Table 2: Results of Income Regression

US Census 2000 US ACS 2006-2010

Mean Std. Dev. Mean Std. Dev.

Individual Characteristics

$\begin{array}{lrrrr}\text { White } & 0.261 & 0.902 & 0.208 & 0.654 \\ \text { Male } & 0.465 & 0.160 & 0.458 & 0.160 \\ \text { High School Dropout } & 9.078 & 1.452 & 9.285 & 1.621 \\ \text { High School Graduate } & 9.306 & 1.374 & 9.578 & 1.529 \\ \text { Some College } & 9.403 & 1.407 & 9.683 & 1.529 \\ \text { College Graduate } & 9.688 & 1.424 & 10.028 & 1.545\end{array}$

Occupations

\begin{tabular}{lrrrr} 
Management & 0.627 & 1.069 & 0.620 & 1.372 \\
Business operations & 0.450 & 1.073 & 0.475 & 1.374 \\
Financial & 0.445 & 1.046 & 0.489 & 1.365 \\
Computer and mathematical & 0.491 & 1.012 & 0.544 & 1.383 \\
Architecture and engineering & 0.509 & 1.027 & 0.526 & 1.345 \\
Life physical and social science & 0.350 & 1.059 & 0.381 & 1.302 \\
Community and social services & 0.125 & 1.084 & 0.144 & 1.370 \\
Legal & 0.529 & 0.981 & 0.566 & 1.259 \\
Education training and library & 0.163 & 1.094 & 0.105 & 1.405 \\
Arts, design, entertainment, sports and media & 0.156 & 1.035 & 0.055 & 1.404 \\
Healthcare practitioners and technical & 0.649 & 1.110 & 0.668 & 1.396 \\
Healthcare support & 0.030 & 1.094 & -0.002 & 1.405 \\
Protective service & 0.319 & 1.093 & 0.310 & 1.333 \\
Food preparation and serving & -0.256 & 1.132 & -0.435 & 1.406 \\
Building and grounds cleaning and maintenance & -0.172 & 1.106 & -0.306 & 1.422 \\
Personal care and service & -0.253 & 0.953 & -0.400 & 1.416 \\
Sales & 0.304 & 1.088 & 0.209 & 1.390 \\
Office and administrative support & 0.232 & 1.064 & 0.175 & 1.371 \\
Farming, fishing and forestry & -0.106 & 0.847 & -0.110 & 1.175 \\
Construction workers & 0.253 & 1.074 & 0.159 & 1.401 \\
Transportation and material moving & 0.341 & 1.075 & 0.319 & 1.387 \\
Installation maintenance and repair & 0.303 & 1.050 & 0.229 & 1.383 \\
Production & 0.201 & 1.071 & 0.073 & 1.396 \\
& & & & \\
\hline
\end{tabular}

Note: We divided the sample into 1855 bins (265 MSAs by 7 age groups) and used these subsamples to run the income regressions. For the ACS data, there were 266 MSAs left after data cleaning. However, the coefficients estimated using one of the MSA, Jackson Michigan, for households 26-30 years old deviated dramatiaclly from that of the other subsamples. As a results, wage incomes predicted based on these coefficients were out of the reasonable range. Threfore, we droped this MSA here and in further analysis. 
Table 3: Results of Housing Prices Regression

\begin{tabular}{|c|c|c|c|c|}
\hline & \multicolumn{2}{|c|}{ US Census 2000} & \multicolumn{2}{|c|}{ US ACS 2006-2010 } \\
\hline & Coeff. & Std. Err. & Coeff. & Std. Err \\
\hline \multicolumn{5}{|c|}{ Number of rooms (omitted category is 1 room) } \\
\hline 2 & $0.059^{* * *}$ & $(0.005)$ & -0.004 & $(0.006)$ \\
\hline 3 & $0.082^{* * *}$ & $(0.005)$ & $0.015^{* *}$ & $(0.007)$ \\
\hline 4 & $0.085^{* * *}$ & $(0.005)$ & $0.023^{* * *}$ & $(0.007)$ \\
\hline 5 & $0.148^{* * *}$ & $(0.005)$ & $0.069^{* * *}$ & $(0.007)$ \\
\hline 6 & $0.247^{* * *}$ & $(0.005)$ & $0.150^{* * *}$ & $(0.007)$ \\
\hline 7 & $0.357^{* * *}$ & $(0.005)$ & $0.242^{* * *}$ & $(0.007)$ \\
\hline 8 & $0.465^{* * *}$ & $(0.005)$ & $0.329^{* * *}$ & $(0.007)$ \\
\hline $9+$ & $0.659^{* * *}$ & $(0.005)$ & $0.489^{* * *}$ & $(0.007)$ \\
\hline \multicolumn{5}{|c|}{ Number of bedrooms (omitted category is no bedroom) } \\
\hline 1 & $0.052^{* * *}$ & $(0.004)$ & $0.086^{* * *}$ & $(0.006)$ \\
\hline 2 & $0.151^{* * *}$ & $(0.004)$ & $0.232^{* * *}$ & $(0.006)$ \\
\hline 3 & $0.196^{* * *}$ & $(0.004)$ & $0.316^{* * *}$ & $(0.006)$ \\
\hline 4 & $0.272^{* * *}$ & $(0.005)$ & $0.423^{* * *}$ & $(0.006)$ \\
\hline $5+$ & $0.369^{* * *}$ & $(0.005)$ & $0.527^{* * *}$ & $(0.006)$ \\
\hline \multicolumn{5}{|c|}{ Age of structure (omitted category is $51+$ years old) } \\
\hline 0-1 year old & $0.332^{* * *}$ & $(0.002)$ & $0.219^{* * *}$ & $(0.002)$ \\
\hline $2-5$ years & $0.288^{* * *}$ & $(0.001)$ & $0.200^{* * *}$ & $(0.001)$ \\
\hline $6-10$ years & $0.233^{* * *}$ & $(0.001)$ & $0.145^{* * *}$ & $(0.001)$ \\
\hline $11-20$ years & $0.153^{* * *}$ & $(0.001)$ & $0.057^{* * *}$ & $(0.001)$ \\
\hline $21-30$ years & $0.064^{* * *}$ & $(0.001)$ & $-0.018^{* * *}$ & $(0.001)$ \\
\hline $31-40$ years & $0.022^{* * *}$ & $(0.001)$ & $-0.043^{* * *}$ & $(0.001)$ \\
\hline $41-50$ years & $0.002^{*}$ & $(0.001)$ & $-0.053^{* * *}$ & $(0.001)$ \\
\hline \multicolumn{5}{|c|}{ Acreage of property (omitted category is less than 1 acre) } \\
\hline $1-9$ acres & $0.141^{* * *}$ & $(0.001)$ & - & - \\
\hline $10+$ acres & $0.289^{* * *}$ & $(0.002)$ & - & - \\
\hline No kitchen & $-0.161^{* * *}$ & $(0.005)$ & $-0.170^{* * *}$ & $(0.005)$ \\
\hline No plumbing facilities & $-0.116^{* * *}$ & $(0.005)$ & $0.011^{*}$ & $(0.006)$ \\
\hline \multicolumn{5}{|c|}{ Units in structure (omitted category is mobile home or trailer) } \\
\hline Boat, tent, van, other & $-0.240^{* * *}$ & $(0.011)$ & $-0.253^{* * *}$ & $(0.013)$ \\
\hline 1-family house, detached & $0.723^{* * *}$ & $(0.001)$ & $0.788^{* * *}$ & $(0.002)$ \\
\hline 1-family house, attached & $0.585^{* * *}$ & $(0.002)$ & $0.658^{* * *}$ & $(0.002)$ \\
\hline 2-family building & $0.644^{* * *}$ & $(0.002)$ & $0.685^{* * *}$ & $(0.002)$ \\
\hline 3-4 family building & $0.608^{* * *}$ & $(0.002)$ & $0.654^{* * *}$ & $(0.002)$ \\
\hline 5-9 family building & $0.595^{* * *}$ & $(0.002)$ & $0.636^{* * *}$ & $(0.002)$ \\
\hline 10-19 family building & $0.622^{* * *}$ & $(0.002)$ & $0.650^{* * *}$ & $(0.002)$ \\
\hline 20-49 family building & $0.621^{* * *}$ & $(0.002)$ & $0.670^{* * *}$ & $(0.003)$ \\
\hline $50+$ family building & $0.661^{* * *}$ & $(0.002)$ & $0.745^{* * *}$ & $(0.002)$ \\
\hline Constant & $7.623^{* * *}$ & $(0.018)$ & $8.059^{* * *}$ & $(0.020)$ \\
\hline$N$ & & $2,028,488$ & 2,22 &, 206 \\
\hline$R^{2}$ & & 0.523 & & \\
\hline
\end{tabular}


Table 4: Results of Conditional Logit Regression: Wages and Migration Costs

\begin{tabular}{|c|c|c|c|c|c|c|c|}
\hline & \multicolumn{7}{|c|}{ Age groups } \\
\hline & $26-30$ & $31-35$ & $36-40$ & $41-45$ & $46-50$ & $51-55$ & $56-60$ \\
\hline \multicolumn{8}{|c|}{ US Census 2000} \\
\hline \multirow[t]{2}{*}{ Income } & $0.241^{* * *}$ & $0.275^{* * *}$ & $0.316^{* * *}$ & $0.273^{* * *}$ & $0.238^{* * *}$ & $0.174^{* * *}$ & $0.085^{* * *}$ \\
\hline & $\begin{array}{r}(0.020) \\
-2888 * * *\end{array}$ & $\begin{array}{r}(0.021) \\
-2883 * * *\end{array}$ & $\begin{array}{r}(0.023) \\
-2984 * * *\end{array}$ & $\begin{array}{r}(0.02 Z) \\
-2956 * * *\end{array}$ & $\begin{array}{r}(0.020) \\
-2072 * * *\end{array}$ & $\begin{array}{r}(0.018) \\
-2806 * * *\end{array}$ & $\begin{array}{r}(0.011) \\
-2834 * * *\end{array}$ \\
\hline State & $(0.018)$ & $(0.021)$ & $(0.024)$ & $(0.023)$ & $(0.020)$ & $(0.018)$ & $(0.016)$ \\
\hline \multirow[t]{2}{*}{ Census } & $-0.882^{* * *}$ & $-0.877^{* * *}$ & $-0.895^{* * *}$ & $-0.926^{* * *}$ & $-0.953^{* * *}$ & $-0.999 * * *$ & $-1.021^{* * *}$ \\
\hline & $(0.025)$ & $(0.030)$ & $(0.034)$ & $(0.033)$ & $(0.029)$ & $(0.025)$ & $(0.022)$ \\
\hline \multirow[t]{2}{*}{ Macro } & $-0.513^{* * *}$ & $-0.536^{* * *}$ & $-0.450 * * *$ & $-0.449^{* * *}$ & $-0.396 * * *$ & $-0.338 * * *$ & $-0.360 * * *$ \\
\hline & $(0.023)$ & $(0.027)$ & $(0.030)$ & $(0.029)$ & $(0.026)$ & $(0.023)$ & $(0.021)$ \\
\hline \multirow[t]{2}{*}{ State x Kid } & $-0.356^{* * *}$ & $-0.187^{* * *}$ & $-0.063^{* *}$ & $-0.071^{* *}$ & 0.036 & $0.048^{*}$ & 0.000 \\
\hline & $(0.027)$ & $(0.027)$ & $(0.028)$ & $(0.028)$ & $(0.026)$ & $(0.027)$ & $(0.029)$ \\
\hline \multirow[t]{2}{*}{ Census x Kid } & $-0.104^{* * *}$ & $-0.145^{* * *}$ & $-0.104^{* *}$ & $-0.070^{*}$ & $-0.094^{* *}$ & $-0.081^{* *}$ & $-0.099^{* *}$ \\
\hline & $(0.039)$ & $(0.039)$ & $(0.041)$ & $(0.041)$ & $(0.039)$ & $(0.039)$ & $(0.043)$ \\
\hline \multirow[t]{2}{*}{ Macro x Kid } & 0.001 & -0.003 & -0.058 & -0.001 & -0.019 & 0.024 & $0.140^{* * *}$ \\
\hline & $(0.034)$ & $(0.034)$ & $(0.035)$ & $(0.035)$ & $(0.033)$ & $(0.034)$ & $(0.037)$ \\
\hline \multicolumn{8}{|c|}{ US ACS 2006-2010 } \\
\hline \multirow[t]{2}{*}{ Income } & $0.070^{* * *}$ & $0.155^{* * *}$ & $0.221^{* * *}$ & $0.171^{* * *}$ & $0.160^{* * *}$ & $0.155^{* * *}$ & $0.144^{* * *}$ \\
\hline & $(0.016)$ & $(0.016)$ & $(0.018)$ & $(0.019)$ & $(0.020)$ & $(0.019)$ & $(0.041)$ \\
\hline \multirow[t]{2}{*}{ State } & $-2.625^{* * *}$ & $-2.559^{* * *}$ & $-2.585^{* * *}$ & $-2.606^{* * *}$ & -2.671 & $-2.713^{* * *}$ & $-2.633^{*}$ \\
\hline & $(0.015)$ & $(0.018)$ & $(0.021)$ & $(0.020)$ & $(0.018)$ & $(0.016)$ & $(0.014)$ \\
\hline \multirow[t]{2}{*}{ Census } & $-1.088 * * *$ & $-1.077^{* * *}$ & $-1.120^{* * *}$ & $-1.176^{* * *}$ & $-1.134^{* * *}$ & $-1.121^{* * *}$ & $-1.162^{* * *}$ \\
\hline & $(0.021)$ & $(0.026)$ & $(0.030)$ & $(0.030)$ & $(0.026)$ & $(0.023)$ & $(0.020)$ \\
\hline \multirow[t]{2}{*}{ Macro } & $-0.592^{* * *}$ & $-0.562^{* * *}$ & $-0.511^{* * *}$ & $-0.460^{* * *}$ & $-0.459^{* * *}$ & $-0.449^{* * *}$ & $-0.454^{* * *}$ \\
\hline & $(0.021)$ & $(0.025)$ & $(0.028)$ & $(0.028)$ & $(0.025)$ & $(0.022)$ & $(0.019)$ \\
\hline \multirow[t]{2}{*}{ State $\mathrm{x}$ Kid } & $-0.425^{* * *}$ & $-0.293^{* * *}$ & $-0.098^{* * *}$ & $-0.077^{* * *}$ & $0.037^{* * *}$ & $0.116^{* * *}$ & $0.051^{* * *}$ \\
\hline & $(0.024)$ & $(0.024)$ & $(0.025)$ & $(0.024)$ & $(0.023)$ & $(0.023)$ & $(0.026)$ \\
\hline \multirow[t]{2}{*}{ Census x Kid } & $-0.062^{*}$ & $-0.072^{* *}$ & $-0.078^{* *}$ & 0.007 & -0.023 & $-0.121^{* * *}$ & $-0.109 * * *$ \\
\hline & $(0.035)$ & $(0.034)$ & $(0.036)$ & $(0.036)$ & $(0.034)$ & $(0.035)$ & $(0.039)$ \\
\hline \multirow[t]{2}{*}{ Macro x Kid } & $-0.122^{* * *}$ & $-0.120^{* * *}$ & $-0.138^{* * *}$ & $-0.183^{* * *}$ & $-0.190^{* * *}$ & $-0.118^{* * *}$ & -0.056 \\
\hline & $(0.033)$ & $(0.031)$ & $(0.033)$ & $(0.033)$ & $(0.031)$ & $(0.032)$ & $(0.036)$ \\
\hline
\end{tabular}


Table 5: Results of Second-Stage Regression: Climate Variables

\begin{tabular}{|c|c|c|c|c|c|c|c|}
\hline & \multicolumn{7}{|c|}{ Age groups } \\
\hline & $26-30$ & $31-35$ & $36-40$ & $41-45$ & $46-50$ & $51-55$ & $56-60$ \\
\hline \multicolumn{8}{|c|}{ US Census 2000} \\
\hline \multirow[t]{2}{*}{ Hot days } & $-0.010^{* * *}$ & $-0.012^{* * *}$ & $-0.012^{* * *}$ & $-0.011^{* * *}$ & $-0.009^{* * *}$ & $-0.008^{* * *}$ & $-0.012^{* * *}$ \\
\hline & $(0.003)$ & $(0.003)$ & $(0.003)$ & $(0.002)$ & $(0.003)$ & $(0.003)$ & $(0.003)$ \\
\hline \multirow[t]{2}{*}{ Cold days } & -0.003 & 0.000 & 0.001 & 0.001 & 0.002 & 0.004 & 0.006 \\
\hline & $(0.004)$ & $(0.004)$ & $(0.004)$ & $(0.004)$ & $(0.004)$ & $(0.004)$ & $(0.004)$ \\
\hline \multirow[t]{2}{*}{ Avg. temp. } & -0.698 & -0.212 & -0.141 & -0.367 & -0.384 & -0.315 & 0.840 \\
\hline & $(1.056)$ & $(1.052)$ & $(1.031)$ & $(1.013)$ & $(1.052)$ & $(1.040)$ & $(1.035)$ \\
\hline \multirow[t]{2}{*}{ Relative humidity } & 0.006 & -0.149 & -0.242 & -0.548 & -0.458 & -0.644 & -0.619 \\
\hline & $(0.486)$ & $(0.485)$ & $(0.475)$ & $(0.466)$ & $(0.484)$ & $(0.479)$ & $(0.476)$ \\
\hline \multirow[t]{2}{*}{ Precipitation } & 0.096 & 0.053 & 0.084 & 0.094 & 0.117 & 0.131 & 0.077 \\
\hline & $(0.129)$ & $(0.128)$ & $(0.126)$ & $(0.123)$ & $(0.128)$ & $(0.127)$ & $(0.126)$ \\
\hline \multirow[t]{2}{*}{ Sunshine } & 0.457 & 0.415 & 0.625 & 0.533 & 0.554 & 0.517 & 0.704 \\
\hline & $(0.613)$ & $(0.610)$ & $(0.598)$ & $(0.587)$ & $(0.610)$ & $(0.603)$ & $(0.600)$ \\
\hline \multicolumn{8}{|c|}{ US ACS 2006-2010 } \\
\hline \multirow[t]{2}{*}{ Hot days } & $-0.010^{* * *}$ & $-0.009^{* * *}$ & $-0.010^{* * *}$ & $-0.010^{* * *}$ & $-0.011^{* * *}$ & $-0.011^{* * *}$ & $-0.011^{* * *}$ \\
\hline & $(0.003)$ & $(0.003)$ & $(0.002)$ & $(0.002)$ & $(0.002)$ & $(0.002)$ & $(0.002)$ \\
\hline \multirow[t]{2}{*}{ Cold days } & $0.011^{* * *}$ & $0.007^{*}$ & $0.012^{* * *}$ & $0.009^{* *}$ & $0.011^{* * *}$ & $0.011^{* * *}$ & $0.012^{* * *}$ \\
\hline & $(0.004)$ & $(0.004)$ & $(0.004)$ & $(0.004)$ & $(0.003)$ & $(0.004)$ & $(0.003)$ \\
\hline \multirow[t]{2}{*}{ Avg. temp. } & $1.787^{*}$ & 1.076 & $2.017^{* *}$ & 1.281 & $1.632^{*}$ & 1.520 & 1.546 \\
\hline & $(1.077)$ & $(1.023)$ & $(0.986)$ & $(0.997)$ & $(0.951)$ & $(0.990)$ & $(0.958)$ \\
\hline \multirow[t]{2}{*}{ Relative humidity } & -0.510 & -0.045 & -0.405 & -0.340 & -0.525 & -0.291 & -0.446 \\
\hline & $(0.491)$ & $(0.466)$ & $(0.449)$ & $(0.454)$ & $(0.433)$ & $(0.451)$ & $(0.436)$ \\
\hline \multirow[t]{2}{*}{ Precipitation } & 0.154 & -0.012 & 0.084 & 0.063 & 0.144 & 0.051 & 0.130 \\
\hline & $(0.131)$ & $(0.125)$ & $(0.120)$ & $(0.121)$ & $(0.116)$ & $(0.121)$ & $(0.117)$ \\
\hline \multirow[t]{2}{*}{ Sunshine } & -0.266 & 0.081 & -0.298 & 0.005 & 0.146 & 0.359 & 0.576 \\
\hline & $(0.618)$ & $(0.587)$ & $(0.566)$ & $(0.572)$ & $(0.546)$ & $(0.568)$ & $(0.550)$ \\
\hline
\end{tabular}

Hot days defined as days per year in which the mean daily temperature exceeds $28^{\circ} \mathrm{C}$. Regional fixed effects defined as USDA plant hardiness zones. ${ }^{* * *} \mathrm{p}<0.01,{ }^{* *} \mathrm{p}<0.05,{ }^{*} \mathrm{p}<0.1$ 
Table 6: Results of Conditional Logit Regression: Other Variables

\begin{tabular}{|c|c|c|c|c|c|c|c|}
\hline & \multicolumn{7}{|c|}{ Age groups } \\
\hline & $26-30$ & $31-35$ & $36-40$ & $41-45$ & $46-50$ & $51-55$ & $56-60$ \\
\hline \multicolumn{8}{|c|}{ US Census 2000} \\
\hline Cold X CA & $\begin{array}{r}0.017^{* * *} \\
(0.001)\end{array}$ & $\begin{array}{r}0.020^{* * *} \\
(0.001)\end{array}$ & $\begin{array}{r}0.019^{* * *} \\
(0.001)\end{array}$ & $\begin{array}{r}0.020^{* * *} \\
(0.001)\end{array}$ & $\begin{array}{r}0.019^{* * *} \\
(0.001)\end{array}$ & $\begin{array}{r}0.019^{* * *} \\
(0.001)\end{array}$ & $\begin{array}{r}0.020^{* * *} \\
(0.001)\end{array}$ \\
\hline \multirow{2}{*}{ Cold X Midwest } & $0.014^{* * *}$ & $0.014^{* * *}$ & $0.012^{* * *}$ & $0.013^{* * *}$ & $0.011^{* * *}$ & $0.010^{* * *}$ & $0.008^{* * *}$ \\
\hline & $(0.001)$ & $(0.001)$ & $(0.001)$ & $(0.001)$ & $(0.001)$ & $(0.001)$ & $(0.001)$ \\
\hline \multirow{2}{*}{ Cold X Northeast } & 0.000 & 0.001 & & $0.002^{2}$ & $0.002^{* * *}$ & 0.00 & $0.002^{* * *}$ \\
\hline & $(0.001)$ & $(0.001)$ & $(0.001)$ & $(0.001)$ & $(0.001)$ & $(0.001)$ & $(0.001)$ \\
\hline \multirow[t]{2}{*}{ Cold X West } & 0.001 & $0.002^{* * *}$ & 0.0 & 0.0 & 0. & & $-0.001^{*}$ \\
\hline & $(0.001)$ & $(0.001)$ & $(0$. & $(0.1$ & $(0.1$ & $(0$. & $(0.001)$ \\
\hline \multirow[t]{2}{*}{ Cold X College } & $-0.004^{* * *}$ & $-0.004^{* * *}$ & $-0.006^{* * *}$ & $-0.007 * * *$ & $-0.008^{* * *}$ & $-0.009^{* * *}$ & $-0.010^{* * *}$ \\
\hline & $(0.000)$ & $(0.000)$ & $(0$. & $(0.000)$ & $(0.000)$ & $(0.000)$ & $(0.000)$ \\
\hline \multirow[t]{2}{*}{ Hot X CA } & $0.029^{* * *}$ & $0.032^{* * *}$ & 0.033 & 0.031 & $0.031^{* * *}$ & $0.030^{* * *}$ & $0.034^{* * *}$ \\
\hline & $(0.001)$ & (ח) & & & & & \\
\hline \multirow[t]{2}{*}{ Hot X Midwest } & $0.017^{* * *}$ & $0.021^{* * *}$ & 0.020 & 0.020 & $0.019^{* * *}$ & $0.018^{* * *}$ & $0.019^{* * *}$ \\
\hline & $(0.001)$ & $(0.001)$ & & & & & $(0.001)$ \\
\hline \multirow[t]{2}{*}{ Hot X Northeast } & $-0.019 * * *$ & $-0.014^{* * *}$ & $-0.015^{* * *}$ & $-0.013^{* * *}$ & $-0.013^{* * *}$ & $-0.012^{* * *}$ & $-0.010^{* * *}$ \\
\hline & $(0.001)$ & $(0.001)$ & & & $(0.001)$ & & $(0.001)$ \\
\hline \multirow[t]{2}{*}{ Hot X West } & $0.018^{* * *}$ & $0.019^{* * *}$ & $0.019^{* * *}$ & $0.016^{* * *}$ & $0.014^{* * *}$ & $0.012^{* * *}$ & $0.012^{* * *}$ \\
\hline & $(0.001)$ & $(0.001)$ & & & $(0.001)$ & $(0.001)$ & $(0.001)$ \\
\hline \multirow[t]{2}{*}{ Hot X College } & $-0.003^{* * *}$ & $-0.002^{* * *}$ & $-0.002^{* * *}$ & $-0.003^{* * *}$ & $-0.003^{* * *}$ & $-0.003^{* * *}$ & $-0.003^{* * *}$ \\
\hline & $(0.000)$ & $(0.000)$ & $(0.000)$ & $(0.000)$ & $(0.000)$ & $(0.000)$ & $(0.000)$ \\
\hline \multicolumn{8}{|c|}{ US ACS 2006-2010 } \\
\hline \multirow[t]{2}{*}{ Cold X CA } & $0.015^{* * *}$ & $0.016^{* * *}$ & 0.016 & $0.018^{* * *}$ & $0.019^{* * *}$ & $0.019^{* * *}$ & $0.018^{* * *}$ \\
\hline & & & & & & & \\
\hline \multirow[t]{2}{*}{ Cold X Midwest } & $0.006^{* * *}$ & $0.005^{* * *}$ & $0.005^{* * *}$ & $0.005^{* * *}$ & $0.005^{* * *}$ & $0.005^{* * *}$ & $0.004^{* * *}$ \\
\hline & & & & & & & \\
\hline \multirow[t]{2}{*}{ Cold X Northeast } & $-0.006^{* * *}$ & $-0.006^{* * *}$ & $-0.006^{* * *}$ & $-0.004^{* * *}$ & $-0.003^{* * *}$ & $-0.004^{* * *}$ & $-0.004^{* * *}$ \\
\hline & & & & & & & \\
\hline \multirow[t]{2}{*}{ Cold X West } & $-0.002^{* * *}$ & $-0.001^{*}$ & $-0.002^{* *}$ & $-0.002^{* *}$ & $-0.002^{* * *}$ & $-0.003^{* * *}$ & $-0.003^{* * *}$ \\
\hline & & & & & & & \\
\hline Cold X College & $-0.004^{* * *}$ & $-0.005^{* * *}$ & $-0.005^{* * *}$ & $-0.005^{* * *}$ & $-0.007 * * *$ & $-0.007^{* * *}$ & $-0.008^{* * *}$ \\
\hline & & & & & & & \\
\hline Hot X CA & $0.027^{* * *}$ & $0.028^{* * *}$ & $0.026^{* * *}$ & $0.027^{* * *}$ & $0.028^{* * *}$ & $0.026^{* * *}$ & $0.027^{* * *}$ \\
\hline & & & & & & & \\
\hline Hot X Midwest & $0.012^{* * *}$ & $0.012^{* * *}$ & $0.013^{* * *}$ & $0.013^{* * *}$ & $0.014^{* * *}$ & $0.014^{* * *}$ & $0.014^{* * *}$ \\
\hline & & & & & & & \\
\hline Hot X Northeast & $0.004^{* * *}$ & $0.004^{* * *}$ & $0.005^{* * *}$ & $0.006^{* * *}$ & $0.007^{* * *}$ & $0.008^{* * *}$ & $0.007^{* * *}$ \\
\hline & & & & & & & \\
\hline Hot X West & $0.004^{* * *}$ & $0.004^{* * *}$ & $0.005^{* * *}$ & $0.005^{* * *}$ & $0.004^{* * *}$ & $0.004^{* * *}$ & $0.004^{* * *}$ \\
\hline & & & & & & & \\
\hline Hot X College & $-0.004^{* * *}$ & $-0.004^{* * *}$ & $-0.003^{* * *}$ & $-0.002^{* * *}$ & $-0.003^{* * *}$ & $-0.003^{* * *}$ & $-0.003^{* * *}$ \\
\hline & $(0.001)$ & $(0.000)$ & $(0.000)$ & $(0.000)$ & $(0.000)$ & $(0.000)$ & $(0.000)$ \\
\hline
\end{tabular}

Hot days defined as days per year in which the mean daily temperature exceeds $28^{\circ} \mathrm{C}$. Climate of origin defined as USDA plant hardiness zones. ${ }^{* * *} \mathrm{p}<0.01,{ }^{* *} \mathrm{p}<0.05,{ }^{*} \mathrm{p}<0.1$ 


\section{$7 \quad$ Figures}

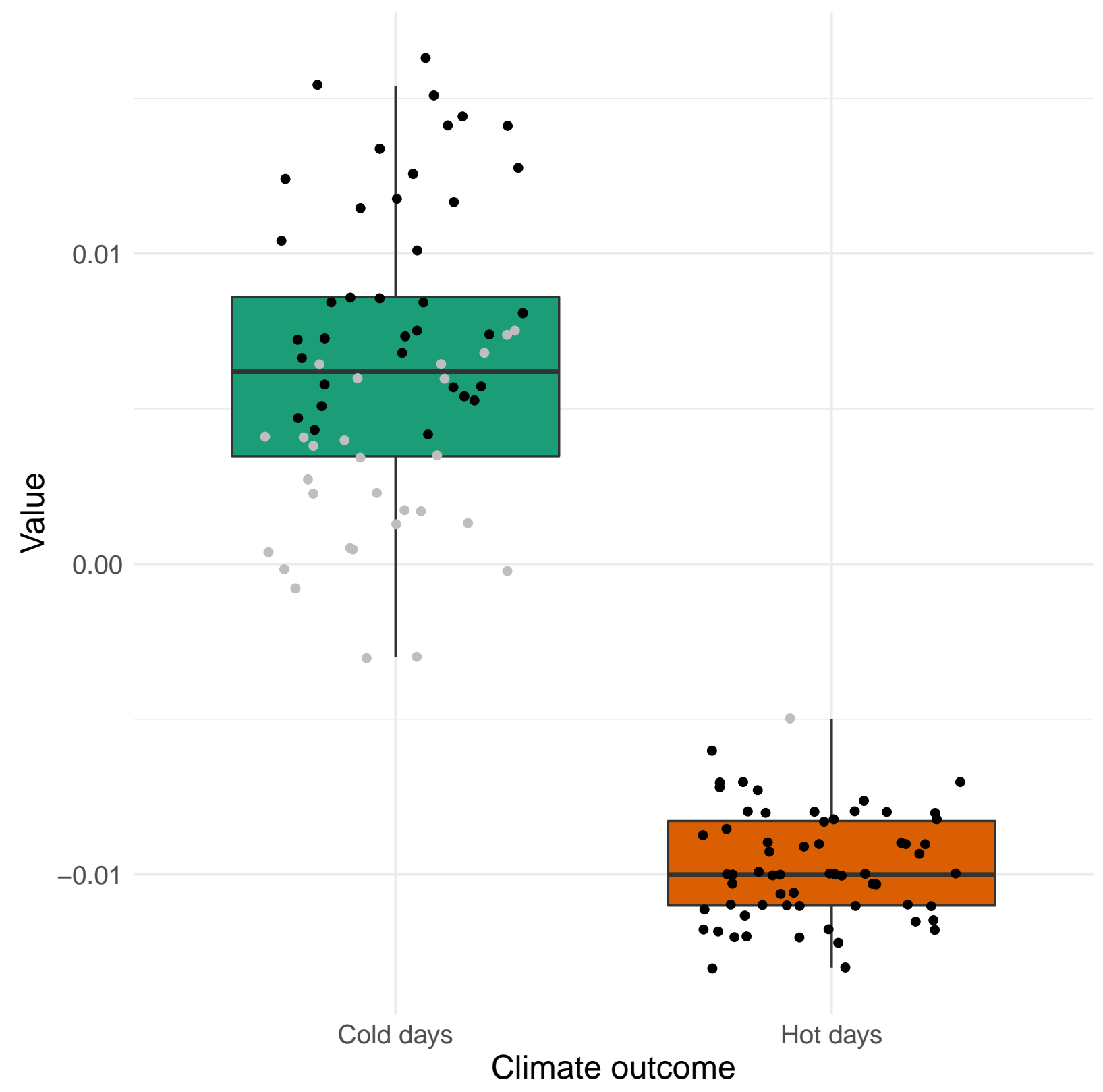

Figure 1: Estimates of hot days and cold days - all specifications using $28^{\circ} \mathrm{C}$ heat definition and USDA climate-zone fixed effects 


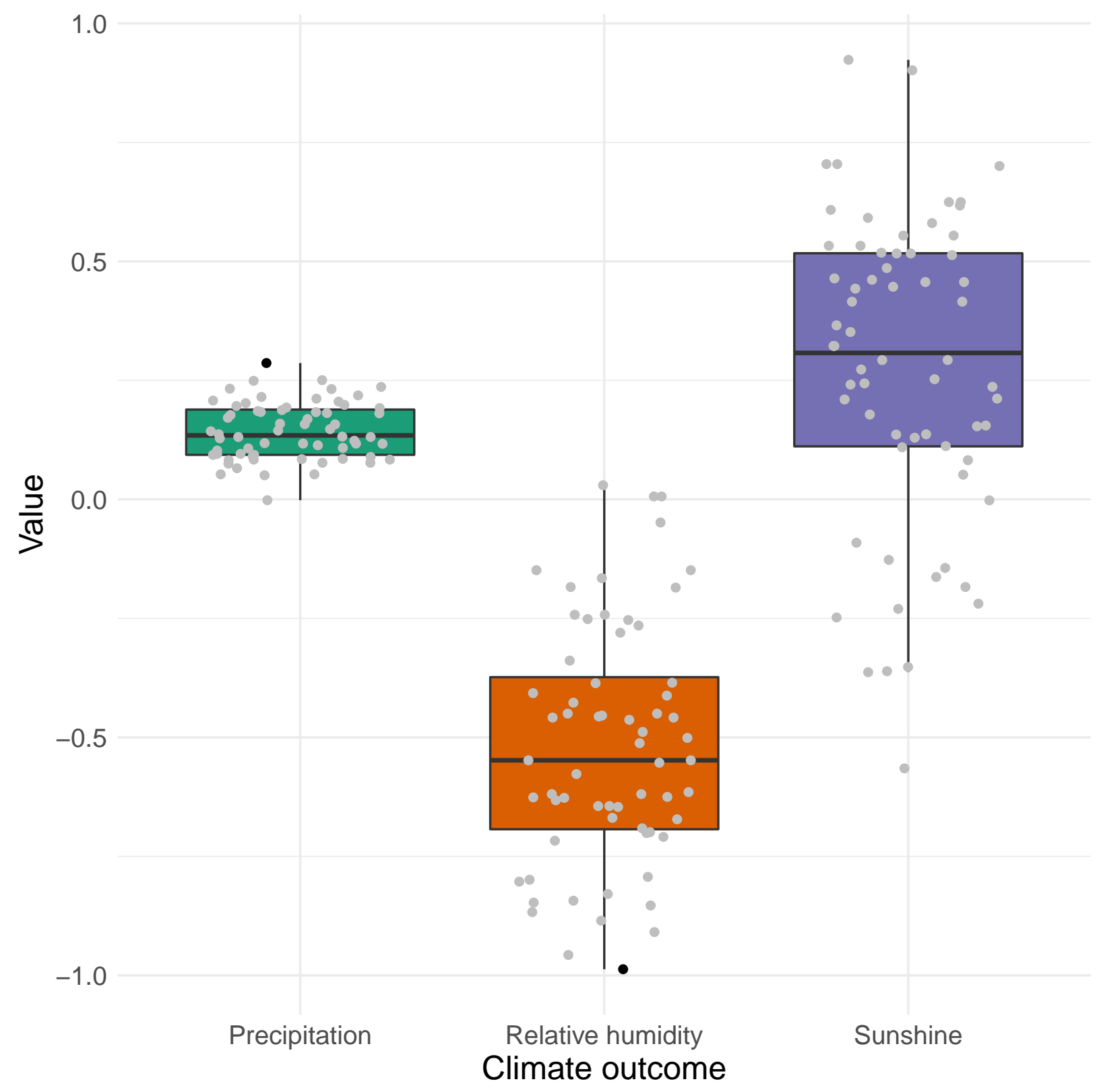

Figure 2: Estimates of "other" climate amenities — all specifications using $28^{\circ} \mathrm{C}$ heat definition and USDA climate-zone fixed effects 


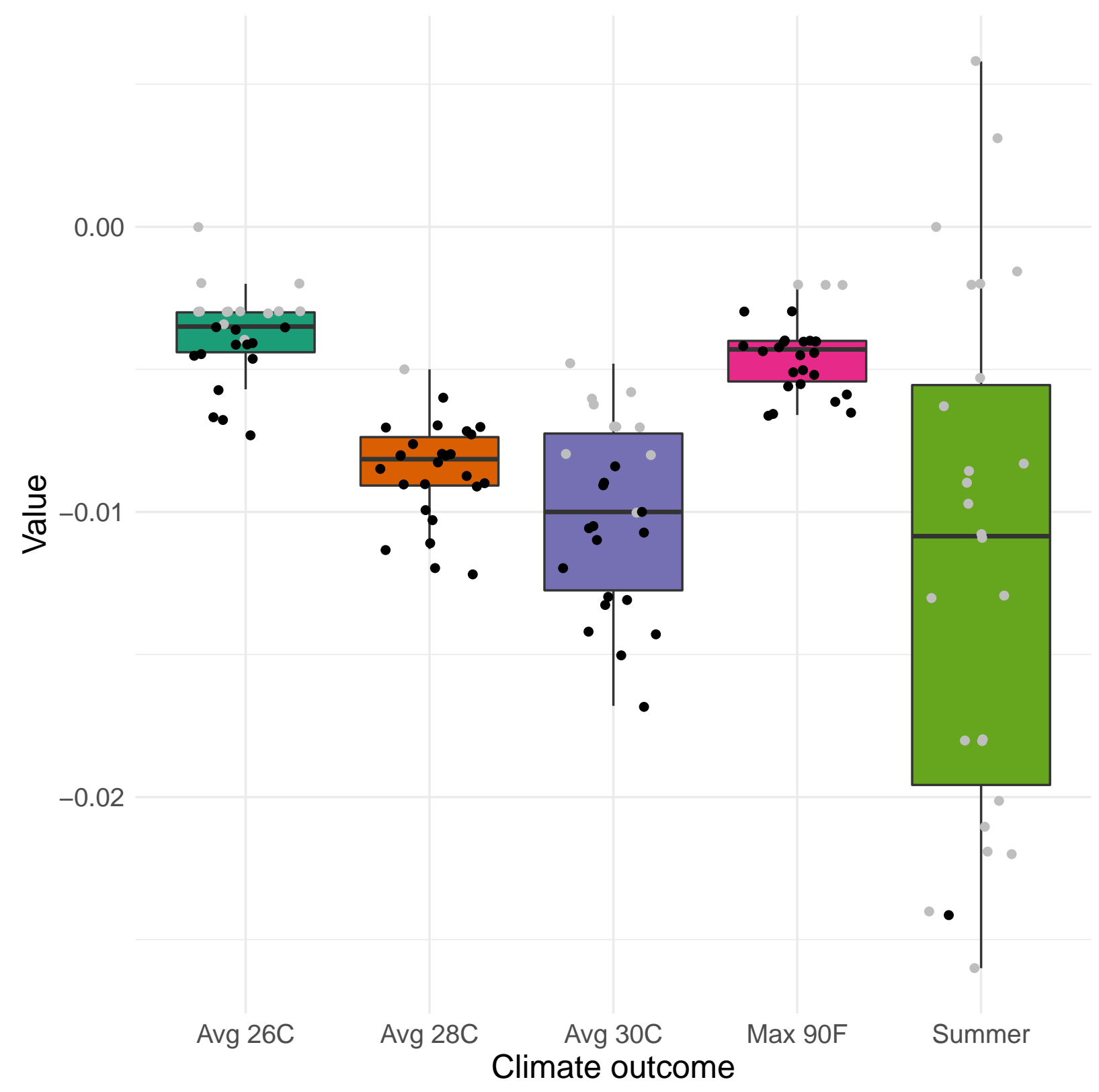

Figure 3: Estimates of alternative heat measures - all specifications using USDA climatezone fixed effects and no average annual temperature variable included 


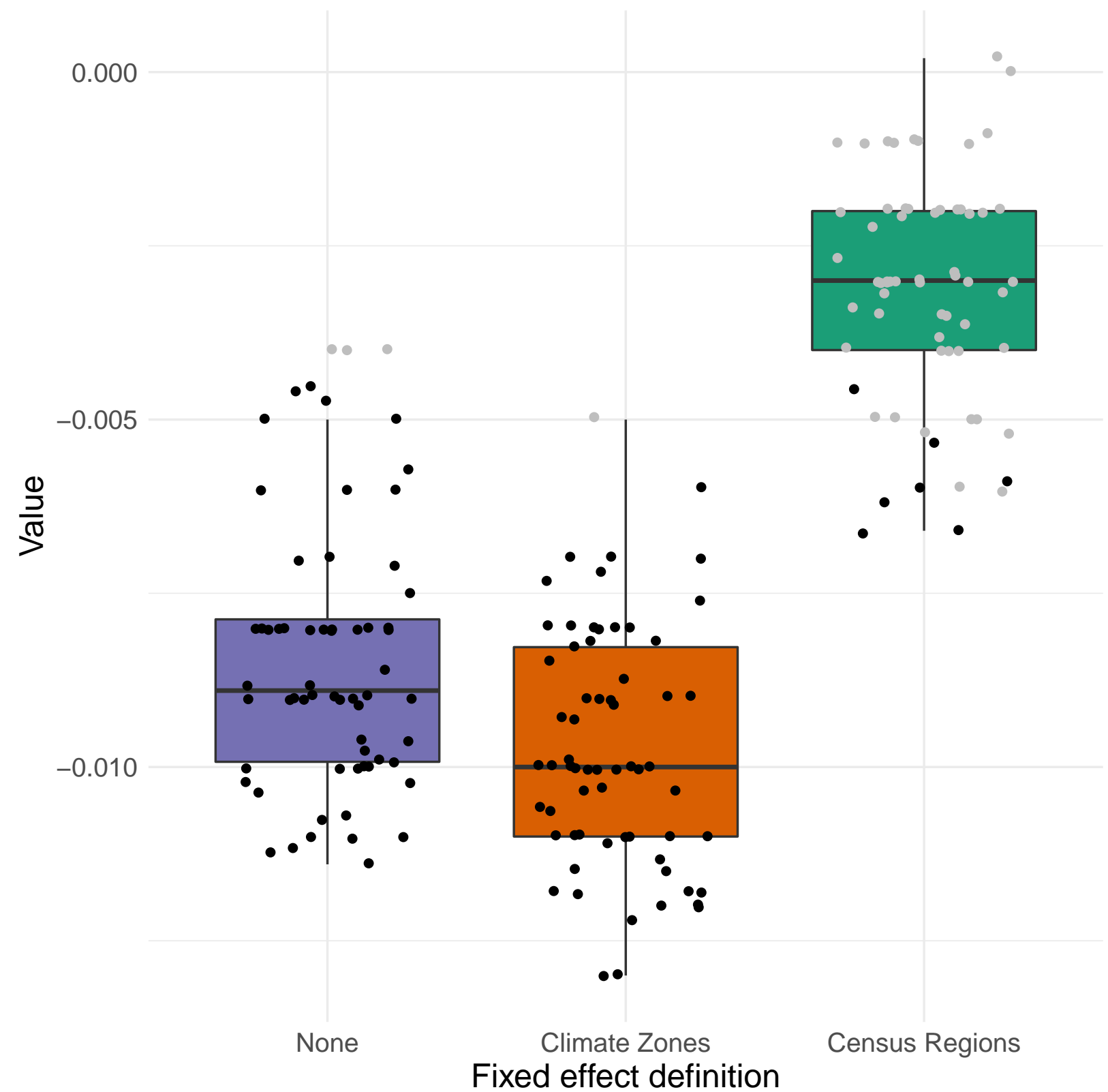

Figure 4: Estimates of alternative fixed-effect definitions - all specifications using $28^{\circ} \mathrm{C}$ heat definition 


\section{A Results for non-climate, second-stage regression vari- ables}

Table 7: Results of Second-Stage Regression: Other Variables, 2000 Decennial Census

\begin{tabular}{|c|c|c|c|c|c|c|c|}
\hline & \multicolumn{7}{|c|}{ Age groups } \\
\hline & $26-30$ & $31-35$ & $36-40$ & $41-45$ & $46-50$ & $51-55$ & $56-60$ \\
\hline \multirow[t]{2}{*}{ Inv. dist. from lake } & $-2.336^{* *}$ & $-2.068^{*}$ & $-1.990^{*}$ & $-2.068^{*}$ & $-2.040^{*}$ & -1.660 & -1.150 \\
\hline & (1.098) & $(1.094)$ & $(1.071)$ & $(1.053)$ & $(1.093)$ & $(1.081)$ & $(1.075)$ \\
\hline \multirow[t]{2}{*}{ Inv. dist. from lake (sqd) } & $1.042^{*}$ & $0.911^{*}$ & $0.888^{*}$ & $0.928^{*}$ & $0.921^{*}$ & 0.752 & 0.525 \\
\hline & $(0.534)$ & $(0.532)$ & $(0.521)$ & $(0.512)$ & $(0.532)$ & $(0.525)$ & $(0.523)$ \\
\hline \multirow[t]{2}{*}{ Inv. dist. from sea } & $-1.829 * * *$ & $-1.643^{* * *}$ & $-1.687^{* * *}$ & $-1.466^{* * *}$ & $-1.567^{* * *}$ & $-1.255^{* *}$ & $-1.393^{* *}$ \\
\hline & $(0.584)$ & $(0.582)$ & $(0.570)$ & $(0.560)$ & $(0.582)$ & $(0.575)$ & $(0.572)$ \\
\hline \multirow[t]{2}{*}{ Inv. dist. from sea (sqd) } & $0.874^{* * *}$ & $0.807^{* * *}$ & $0.836^{* * *}$ & $0.742^{* * *}$ & $0.790 * * *$ & $0.648^{* *}$ & $0.725^{* * *}$ \\
\hline & $(0.281)$ & $(0.280)$ & $(0.274)$ & $(0.270)$ & $(0.280)$ & $(0.277)$ & $(0.275)$ \\
\hline \multirow[t]{2}{*}{ Slope } & 0.011 & 0.017 & 0.009 & 0.002 & 0.015 & -0.004 & 0.022 \\
\hline & $(0.047)$ & $(0.047)$ & $(0.046)$ & $(0.045)$ & $(0.047)$ & $(0.046)$ & $(0.046)$ \\
\hline \multirow[t]{2}{*}{ Crime rates } & 0.095 & 0.050 & -0.004 & 0.027 & 0.040 & 0.059 & 0.070 \\
\hline & $(0.126)$ & $(0.125)$ & $(0.123)$ & $(0.121)$ & $(0.125)$ & $(0.124)$ & $(0.123)$ \\
\hline \multirow[t]{2}{*}{ Gvt. expenditure } & 0.101 & 0.149 & $0.173^{*}$ & $0.251^{* *}$ & $0.230^{* *}$ & $0.271^{* * *}$ & $0.197^{* *}$ \\
\hline & $(0.102)$ & $(0.102)$ & $(0.099)$ & $(0.098)$ & $(0.102)$ & $(0.100)$ & $(0.100)$ \\
\hline \multirow[t]{2}{*}{ Income } & -0.017 & 0.097 & 0.060 & 0.075 & 0.125 & 0.157 & 0.150 \\
\hline & $(0.196)$ & $(0.195)$ & $(0.191)$ & $(0.188)$ & $(0.195)$ & $(0.193)$ & $(0.192)$ \\
\hline \multirow[t]{2}{*}{ Manufacturing est. } & 0.183 & $0.274^{* *}$ & $0.288^{* * *}$ & $0.369 * * *$ & $0.307^{* * *}$ & $0.336^{* * *}$ & $0.381^{* * *}$ \\
\hline & $(0.111)$ & $(0.111)$ & $(0.108)$ & $(0.107)$ & $(0.111)$ & $(0.109)$ & $(0.109)$ \\
\hline \multirow[t]{2}{*}{ Percentage of White } & $-0.464^{*}$ & $-0.473^{*}$ & $-0.441^{*}$ & -0.336 & -0.326 & -0.159 & -0.104 \\
\hline & $(0.270)$ & $(0.269)$ & $(0.264)$ & $(0.259)$ & $(0.269)$ & $(0.266)$ & $(0.265)$ \\
\hline \multirow[t]{2}{*}{ Population } & $0.805^{* * *}$ & $0.696^{* * *}$ & $0.663^{* * *}$ & $0.558 * * *$ & $0.621^{* * *}$ & $0.590 * * *$ & $0.541^{* * *}$ \\
\hline & $(0.119)$ & $(0.119)$ & $(0.116)$ & $(0.114)$ & $(0.119)$ & $(0.117)$ & $(0.117)$ \\
\hline \multirow[t]{2}{*}{ Property tax rates } & -0.165 & -0.036 & 0.041 & 0.036 & 0.087 & 0.086 & 0.100 \\
\hline & $(0.124)$ & $(0.123)$ & $(0.121)$ & $(0.119)$ & $(0.123)$ & $(0.122)$ & $(0.121)$ \\
\hline$N$ & 257 & 257 & 257 & 257 & 257 & 257 & 257 \\
\hline$R^{2}$ & 0.890 & 0.891 & 0.891 & 0.892 & 0.884 & 0.883 & 0.885 \\
\hline
\end{tabular}


Table 8: Results of Second-stage Regression: Other Variables, 2006-2010 ACS

\begin{tabular}{|c|c|c|c|c|c|c|c|}
\hline & \multicolumn{7}{|c|}{ Age groups } \\
\hline & $26-30$ & $31-35$ & $36-40$ & $41-45$ & $46-50$ & $51-55$ & $56-60$ \\
\hline \multirow[t]{2}{*}{ Inv. dist. from lake } & $-2.342^{* *}$ & $-1.791^{*}$ & $-1.822^{*}$ & $-1.584^{*}$ & $-2.348^{* *}$ & $-2.209^{* *}$ & $-2.527^{* *}$ \\
\hline & $(1.115)$ & $(1.058)$ & $(1.020)$ & $(1.031)$ & $(0.984)$ & $(1.024)$ & $(0.991)$ \\
\hline \multirow[t]{2}{*}{ Inv. dist. from lake (sqd) } & $1.061^{*}$ & 0.796 & 0.813 & 0.711 & $1.093^{* *}$ & $1.025^{* *}$ & $1.183^{* *}$ \\
\hline & $(0.542)$ & $(0.514)$ & $(0.495)$ & $(0.501)$ & $(0.478)$ & $(0.498)$ & $(0.481)$ \\
\hline \multirow[t]{2}{*}{ Inv. dist. from sea } & -0.944 & -0.653 & -0.591 & -0.435 & -0.688 & -0.439 & -0.454 \\
\hline & $(0.574)$ & $(0.546)$ & $(0.526)$ & $(0.532)$ & $(0.507)$ & $(0.528)$ & $(0.511)$ \\
\hline \multirow[t]{2}{*}{ Inv. dist. from sea (sqd) } & 0.445 & 0.311 & 0.288 & 0.224 & 0.351 & 0.239 & 0.252 \\
\hline & $(0.276)$ & $(0.262)$ & $(0.253)$ & $(0.256)$ & $(0.244)$ & $(0.254)$ & $(0.246)$ \\
\hline \multirow[t]{2}{*}{ Slope } & $0.093^{*}$ & $0.093^{* *}$ & $0.093^{* *}$ & $0.073^{* *}$ & $0.074^{*}$ & 0.072 & 0.060 \\
\hline & $(0.048)$ & $(0.046)$ & $(0.044)$ & $(0.044)$ & $(0.042)$ & $(0.044)$ & $(0.043)$ \\
\hline \multirow[t]{2}{*}{ Crime rates } & 0.051 & 0.002 & -0.001 & -0.033 & -0.068 & -0.049 & -0.013 \\
\hline & $(0.128)$ & $(0.121)$ & (0.117) & (0.118) & $(0.113)$ & (0.117) & $(0.113)$ \\
\hline \multirow[t]{2}{*}{ Gvt. expenditure } & 0.062 & 0.041 & 0.063 & 0.121 & $0.181^{* *}$ & $0.232^{* *}$ & $0.188^{* *}$ \\
\hline & $(0.103)$ & (0.098) & (0.094) & (0.095) & $(0.091)$ & $(0.095)$ & $(0.092)$ \\
\hline \multirow[t]{2}{*}{ Income } & 0.046 & -0.045 & 0.076 & 0.179 & 0.177 & 0.213 & 0.221 \\
\hline & (0.197) & $(0.187)$ & $(0.180)$ & (0.182) & $(0.174)$ & $(0.181)$ & $(0.175)$ \\
\hline \multirow[t]{2}{*}{ Manufacturing est. } & -0.010 & 0.057 & $0.181^{*}$ & $0.197^{*}$ & $0.224^{* *}$ & $0.281^{* * *}$ & $0.243^{* *}$ \\
\hline & $(0.113)$ & $(0.107)$ & $(0.103)$ & $(0.104)$ & $(0.099)$ & $(0.103)$ & $(0.100)$ \\
\hline \multirow[t]{2}{*}{ Percentage of White } & $-0.553^{* *}$ & $-0.440^{*}$ & $-0.476^{*}$ & $-0.422^{*}$ & -0.375 & -0.404 & -0.198 \\
\hline & $(0.274)$ & $(0.260)$ & $(0.251)$ & $(0.253)$ & $(0.242)$ & $(0.252)$ & $(0.244)$ \\
\hline \multirow[t]{2}{*}{ Population } & $0.944^{* * *}$ & $0.897^{* * *}$ & $0.739 * * *$ & $0.708^{* * *}$ & $0.654^{* * *}$ & $0.599^{* * *}$ & $0.622^{* * *}$ \\
\hline & $(0.122)$ & $(0.115)$ & $(0.111)$ & $(0.112)$ & $(0.107)$ & $(0.111)$ & $(0.107)$ \\
\hline \multirow[t]{2}{*}{ Property tax rates } & -0.046 & -0.018 & 0.078 & 0.086 & 0.138 & $0.204^{*}$ & $0.221^{*}$ \\
\hline & $(0.126)$ & $(0.119)$ & $(0.115)$ & $(0.116)$ & $(0.111)$ & $(0.116)$ & $(0.112)$ \\
\hline$N$ & 257 & 257 & 257 & 257 & 257 & 257 & 257 \\
\hline$R^{2}$ & 0.860 & 0.871 & 0.877 & 0.875 & 0.884 & 0.876 & 0.880 \\
\hline
\end{tabular}

